\title{
Processing of English inflectional morphology
}

\author{
JOAN A. SERENO and ALLARD JONGMAN \\ Cormell University, Ithaca, New York
}

\begin{abstract}
The present paper explores the representation of inflectional morphology in the English lexicon. There has been a long-standing debate about how these inflectional relationships might be involved during on-line processing. Inflected forms may be derived from an uninflected base form by rule application; by contrast, both regular and irregular inflection may be treated in the same way, with morphological patterns emerging from mappings between base and inflected forms. The present series of experiments investigated these issues using a lexical decision task. The first experiment showed that response latencies to nouns were significantly shorter than those to verbs. A possible explanation for these results can be found in differences in inflectional structure between English nouns and verbs. Namely, the relative frequency of uninflected compared with inflected forms is greater for nouns than for verbs. Two additional experiments compared noun stimuli with different inflectional structures. In all cases, differences in response latencies were predicted by the frequency of the surface form, whether uninflected or inflected. The pattern of results lends support for a unitary associative system for processing regular inflection of nouns in English and argues against the view that regular inflected plurals are derived by rule from a single, uninflected lexical entry.
\end{abstract}

The role of morphological structure in the mental lexicon has been much debated, with respect to both the composition of lexical entries and the process by which sensory information is matched to these internal representations (for reviews, see Butterworth, 1983; Feldman, 1995; Henderson, 1985; Marslen-Wilson, Tyler, Waksler, \& Older, 1994; McQueen \& Cutler, in press; Sandra, 1994; Taft, 1991). The basic question addressed is how morphological relations among words are relevant in the perception and production of language.

Although numerous studies have examined morphological issues, the results are far from conclusive. In general, two basic positions have emerged. At one extreme, arguments have been presented that support a full listing of all morphologically complex forms in the lexicon (Butterworth, 1983; Manelis \& Tharp, 1977). In such models, lexical access occurs via morphologically complex lexical entries. At the other extreme, there are claims that the input lexicon is morphologically organized. In these models, access occurs via uninflected base forms after affixes are stripped away (Taft, 1985; Taft \& Forster, 1975). Many recent models incorporate features from both of these positions, allowing both holistic and decomposed morphological representation and processing (Caramazza, Laudanna, \& Romani, 1988; Frauenfelder \& Schreuder,

We would like to thank Cisca Custers and Toine Thissen for assistance in stimulus preparation and Scott Gargash and John Mertus for technical help. The comments on an earlier draft by Steve Pinker, Kathryn Spoehr, and an anonymous reviewer were helpful. We would also like to thank the Brown University Phonetics Laboratory for use of its facilities. Preliminary reports of this research were presented at the Linguistic Society of America (1991) and at the CUNY Conference on Human Sentence Processing (1992). Correspondence should be addressed to J. A. Sereno, Department of Modern Languages, Morrill Hall, Cornell University, Ithaca, NY 14853 (e-mail: joan.sereno@cornell.edu).
1992; Schreuder \& Baayen, 1994; Schriefers, Friederici, \& Graetz, 1992; Zwitserlood, 1994). The present research investigates the representation of inflectional morphological relationships and the role of such representations in recognition. A major issue addressed is whether regularly inflected words in English are listed in the lexicon as morphologically complex forms or whether only uninflected base forms are listed, with morphologically complex forms derived by rule.

Traditionally, morphologically complex words include inflected and derived words (Matthews, 1974). Derivational processes, however, are not fully productive-they generally cannot be applied to every lexical item. In order to make the strongest claims in favor of or against decomposed lexical entries, a fully productive paradigm such as inflectional morphology must be examined. The study of inflectional morphological processes may provide stronger evidence to test hypotheses concerning the morphological organization of the lexicon.

Consider an inflectional process such as the past tense marking of verbs in English. The inflectional system of English displays a highly productive regular process (e.g., walk-walked, kick-kicked) and also a small number of frequently occurring irregular forms (e.g., eat-ate, singsang). This inflectional paradigm has provided the basis for debate on morphological relations in the lexicon.

A number of recent studies have examined such inflectional processes. Taft (1979) compared noun and verb stimuli that contrasted either in terms of surface frequency (the actual frequency of the presented form) or total frequency (the summed frequency of all inflectional variants). He found that when stimuli were contrasted in total frequency, although equated in surface frequency, reaction time (RT) differences were obtained. However, in a second experiment, differences were also found when 
stimuli were contrasted in surface frequency, although equated in total frequency. Taken together, these findings seem contradictory, with both total and surface frequency appearing to influence RTs in a lexical decision task. Burani, Salmaso, and Caramazza (1984) replicated the findings of Taft (1979) in Italian. For Italian, both root-morpheme (total) frequency and surface frequency contribute to lexical decision times.

Kelliher and Henderson (1990) examined irregularly inflected verbs in English. In their experiment, they compared lexical decision latencies across inflected stimuli that were matched in terms of surface frequency but contrasted in total frequency. They found that, even for irregular, inflected stimuli, surface frequency does not appear to determine response latencies but that latencies for past tense inflected forms seem to vary with the frequency of morphologically related words. Although latency varied with total frequency of occurrence, their manipulation did not allow one to distinguish between total frequency and uninflected present tense (i.e., citation form) frequency, since these parameters were highly correlated in their study.

In a series of experiments examining citation form frequency in Serbo-Croatian, a heavily inflected language, Lukatela and colleagues (Lukatela, Carello, \& Turvey, 1987; Lukatela, Gligorijević, Kostić, \& Turvey, 1980; Lukatela et al., 1978) reported the shortest lexical decision latencies for the nominative singular form (even when it is not the most frequent form), whereas latencies were undifferentiated among the oblique cases (i.e., members of an inflectional paradigm other than the citation form). However, Katz, Rexer, and Lukatela (1991) found that in English, surface frequency alone could predict response latencies for both citation forms of verbs and inflected (past tense) forms, although, for present participle forms, total frequency of occurrence was a stronger predictor.

Overall, the results from these inflectional morphology experiments are somewhat inconclusive. This is unfortunate since such studies do have important implications for models of lexical access and representation. Often, these studies have examined the inflectional verb paradigm in English or highly inflected noun paradigms cross-linguistically. In both these cases, the systematic matching of frequency in one form often allows a myriad of possible variations in the other forms. Taft (1979), for example, included both nouns and verbs in determining frequency differences. Consider, for example, Taft's example stimuli sized and raked. Although matched in terms of their past tense frequency, they are also highly similar in terms of their total verb frequency. How they differ is in terms of the contribution of noun frequency, with size having 148 occurrences per million as a noun and rake having only 8 occurrences per million as a noun. Such comparisons contrast not only frequency of uninflected and inflected forms but also grammatical class differences, thus allowing an additional uncontrolled variable. Also, in these experiments, comparisons of uninflected forms used different stimuli than comparisons of inflected forms, allowing stimulus selection to be an additional confounding factor (see Burani et al., 1984, for a similar criticism). Given the design of these experiments, then, the possibility exists that the differences obtained may be due to idiosyncratic differences in the structure of the stimuli that make up each group.

The goal of the present research was to investigate inflectional morphology in order to understand basic organizational principles of the mental lexicon. Specifically, a major issue addressed by this study is whether morphologically complex words are derived by rule from a single, uninflected lexical entry or whether they are stored and accessed separately, with each morphological variant represented by a distinct lexical entry. The experimental method employed allows for the control of potential problems associated with stimulus selection by utilizing the same stimuli for comparisons of uninflected and inflected forms. The frequency of the uninflected stem, the frequency of the inflectional variants, and total frequency of occurrence were independently varied in order to determine the separate contribution of each of these forms to access processes. It was hypothesized that differences among these experimental conditions should reflect the influence of surface frequency and total frequency in a visual lexical decision word recognition task.

Three experiments were conducted. Experiment 1 examined differences in the processing of nouns and verbs. These data were examined in terms of frequency of occurrence of the inflectional variants. In this way, the contrast between nouns and verbs was used to introduce the relevant morphological issues and to motivate the use of a single grammatical class in subsequent experiments. Experiments 2 and 3 then systematically explored inflectional morphological issues in nouns. Specifically, Experiment 2 manipulated frequency of uninflected and inflected forms, holding total frequency constant, whereas Experiment 3 manipulated frequency of inflected forms and total frequency, holding frequency of uninflected forms constant.

\section{EXPERIMENT 1}

In recent years, a variety of factors have been shown to influence word recognition processes. Word frequency (Forster \& Chambers, 1973; Rubenstein, Lewis, \& Rubenstein, 1971; Stanners, Jastrzembski, \& Westbrook, 1975; Whaley, 1978) and associative relatedness (Fischler \& Goodman, 1978; Meyer \& Schvaneveldt, 1971; Warren, 1977) have been typically characterized as playing an important role in lexical access processes (see Sereno, 1991). Few studies, however, have controlled for grammatical class membership effects. This situation is puzzling, considering the fact that the grammatical class of a lexical item has been shown to have a marked effect on response latencies in word recognition studies (Bradley, 1978; Kean, 1977; Sereno \& Jongman, 1990). These syntactic class differences are most pronounced in the distinction, expressed most clearly in the neuropsy- 
chological literature, between function words and content words, suggesting largely distinct recognition procedures for the two word classes (Bradley, 1978; Friederici, 1985; Zurif, 1980). However, there has been much controversy concerning the exact nature of the distribution of function and content words since there is also a sizable frequency difference that distinguishes these two syntactic classes (Gordon \& Caramazza, 1982, 1985).

Outside the area of word recognition, a number of researchers have noted vocabulary class differences within the class of content words. This research has invariably examined the distinction between the syntactic class of nouns and that of verbs (Clark \& Clark, 1977; Gentner, 1981, 1982; Hockett, 1968; Sapir, 1944). Sereno and Jongman (1995), for example, reported systematic acoustic differences (duration, amplitude, and fundamental frequency) between grammatically ambiguous words (such as answer or design), contingent upon their production as a noun or verb. Moreover, a number of neuropsychological studies have reported the selective dysfunction of the categories of noun and verb (Caramazza \& Hillis, 1991; Miceli, Silveri, Villa, \& Caramazza, 1984; Zingeser $\&$ Berndt, 1988). Given this history, the noun-verb distinction seems to be a natural choice as a basic variable that may affect response latencies in word recognition studies.

To investigate these differences, a lexical decision experiment was conducted in which pure nouns (words used only as nouns) and pure verbs (words used only as verbs) were compared. Unlike the function-content contrast, the distribution of nouns and verbs in English is not nearly as frequency skewed (Gentner, 1981). The goal of the present experiment was to determine if grammatical class membership had any systematic effect on processing time in a lexical decision task.

\section{Method}

Subjects. Twenty-four students attending Brown University were paid for their participation in the experiment. All were native speakers of English with normal or corrected-to-normal visual acuity.

Materials. Forty-eight words were selected from the Brown corpus (Francis \& Kučera, 1982) and 48 nonwords were constructed (Appendix A). For the word stimuli, 24 were pure nouns (i.e., in the Brown corpus, these stimuli were used only as nouns and had no occurrences as a verb) and 24 were pure verbs (i.e., in the Brown corpus, these stimuli were used only as verbs and had no occurrences as a noun). The noun and verb stimuli were matched for overall frequency of occurrence with a mean frequency per million of 202 $(S D=99)$ and $202(S D=99)$, respectively. Stimuli were also matched for number of letters (5.4 and 5.5, respectively). In each group, there were 11 monosyllabic and 13 bisyllabic stimuli. For the bisyllabic stimuli, it was difficult to control for stress placement since bisyllabic nouns in English are predominantly stressed on the first syllable and bisyllabic verbs on the second syllable (Kelly \& Bock, 1988; Sereno, 1986; Sereno \& Jongman, 1995). For the bisyllabic pure nouns, 12 of 13 were forestressed whereas 12 of 13 bisyllabic verbs were backstressed.

The 48 nonword stimuli were phonotactically acceptable sequences and were matched to the word stimuli in terms of mean number of letters (5.5) and number of syllables (22 monosyllabic and 26 bisyllabic nonwords).

Design and Procedure. All subjects were tested individually. Subjects were instructed to make a lexical decision to each stimu- lus. For each trial, subjects were to move their index finger from a neutral resting position to one of two equidistantly placed response buttons (labeled "word" and "nonword"). Position of response buttons was counterbalanced across subjects. Subjects were to respond as quickly and accurately as possible. Following instructions, subjects were given a set of 12 practice items to familiarize them with the procedure. The practice items were not used in the test.

Stimulus timing was controlled by an IBM PC/AT running BLISS software (Mertus, 1989). Stimuli were presented on a Panasonic video monitor (Model TR-930) and appeared in the center of the screen in lowercase letters. Stimuli were presented at a fixed rate, with a stimulus onset asynchrony (SOA) of $2 \mathrm{sec}$. Each stimulus item remained on the screen until subjects responded. RT was measured from the onset of the stimuli until a response was made. Immediately following a response, the target item disappeared from the screen. This sequence was repeated for every stimulus item. The entire experiment lasted approximately $15 \mathrm{~min}$.

\section{Results}

Analyses of variance (ANOVAs) were conducted for subjects $\left(F_{1}\right)$ and items $\left(F_{2}\right)$ for both the RT and error data. All means presented were taken from the subject analyses. No errors or RTs greater than $2 S D$ from each subject's mean were included in the analyses. The total number of errors was 48 , representing $2.1 \%$ of all responses.

A one-way ANOVA with repeated measures revealed a main effect of lexical status $\left[F_{1}(1,23)=26.24, M S_{\mathrm{e}}=\right.$ $465.78, p<.001 ; F_{2}(1,94)=31.36, M S_{\mathrm{e}}=993.06, p<$ $.001]$. Response latencies to words $(602 \mathrm{msec})$ were significantly faster than those to nonwords $(633 \mathrm{msec})$.

For the word stimuli, a one-way ANOVA with repeated measures revealed a main effect for condition $\left[F_{1}(1,23)=\right.$ $9.37, M S_{\mathrm{e}}=411.04, p=.006 ; F_{2}(1,46)=7.72, M S_{\mathrm{e}}=$ $543.88, p=.008]$. Subjects responded significantly faster to pure nouns $(592 \mathrm{msec})$ than to pure verbs $(610 \mathrm{msec})$.

The significant difference between nouns and verbs may have been the result of differences in stress placement rather than differences in syntactic class per se, since stress location for bisyllabic nouns and verbs was not balanced. To check this possibility, monosyllabic nouns and verbs were compared to bisyllabic nouns and verbs. A two-way ANOVA (stressed syllable $\times$ grammatical class) was conducted. There was a main effect for stressed syllable $\left[F_{1}(1,23)=6.43, M S_{\mathrm{e}}=755.74, p=\right.$ $\left..018 ; F_{2}(1,44)=4.43, M S_{\mathrm{e}}=515.57, p=.041\right]$. Monosyllabic words $(594 \mathrm{msec})$ were responded to significantly faster than were bisyllabic words $(608 \mathrm{msec})$. As expected, there was also a main effect for grammatical class $\left[F_{1}(1,23)=9.62, M S_{\mathrm{e}}=780.82, p=.005\right.$; $\left.F_{2}(1,44)=7.95, M S_{\mathrm{e}}=515.57, p=.007\right]$. RTs to nouns $(592 \mathrm{msec})$ were significantly faster than RTs to verbs $(610 \mathrm{msec})$. More importantly, though, there was no significant interaction in either the subject or item analyses $\left(F_{\mathrm{S}}<1\right)$. As illustrated in Figure 1, the difference between nouns and verbs for the monosyllabic stimuli was similar to that for the bisyllabic stimuli.

Both subject and item analyses were also conducted for the error data. No significant differences were found either for the word-nonword comparisons or for the noun-verb comparisons. 


\section{Discussion}

The present results showed systematic processing differences between words differing only in grammatical class membership. Lexical decision latencies to nouns were significantly faster than those to verbs. Moreover, the significant differences between nouns and verbs cannot be ascribed to differences in stress placement between the two grammatical categories. Noun-verb differences for bisyllabic stimuli that show contrasting stress placements were similar to noun-verb differences for the monosyllabic stimuli. Unlike the open-closed class distinction, the vocabulary difference between nouns and verbs cannot be attributed to virtually mutually exclusive frequency distributions.

Noun-verb dissociations have been found in children, normal adults, and brain-damaged populations (see Sereno, Slack, \& Jongman, 1996). A number of possible explanations for the noun-verb differences have been proposed, including, most prominently, semantic differences (e.g., abstract-concrete, relational-referential; see, among others, Behrend, 1990; Gentner, 1978; Graesser, Hopkinson, \& Schmid, 1987; Huttenlocher \& Lui, 1979). One important factor that has been less carefully examined is the difference in inflectional structure between nouns and verbs. A potential explanation for the processing differences found in Experiment 1 may be the contrasting inflectional structure of nouns and verbs.

Nouns have singular forms (base forms), and plural and possessive inflectional forms whereas verbs have infinitival forms (base forms) and first-, second-, and third-person forms in both the singular and plural, past tense forms, present participle forms, and past participle forms. Interestingly, the uninflected forms of nouns and verbs drastically differ in terms of their frequency of usage. An analysis of English using data from the Brown corpus (Francis \& Kučera, 1982) revealed that the uninflected form of nouns constitutes $73.6 \%$ of the total frequency of the noun lemma whereas the uninflected form of verbs constitutes only $29.3 \%$ of the total verb lemma (Sereno \& Jongman, 1992). In Experiment 1, the percent-

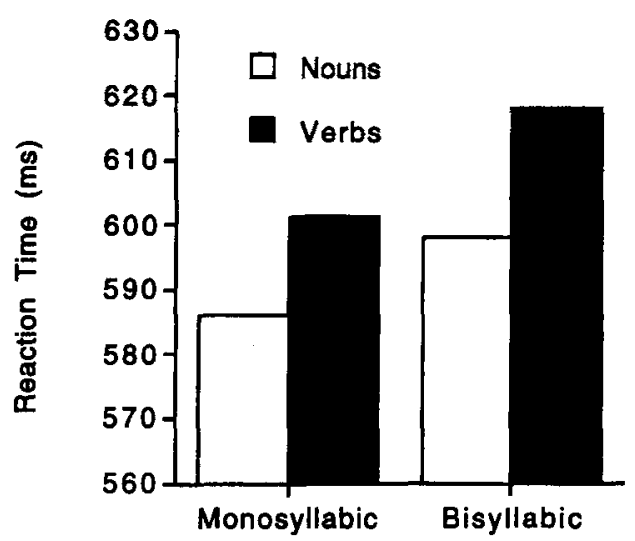

Figure 1. Mean lexical decision times (in milliseconds) for monosyllabic and bisyllabic nouns and verbs used in Experiment 1. age of the base form frequency to total frequency was characteristic of the overall language statistics, with the noun base forms constituting $74 \%$ of noun lemmata and verb base forms comprising $34 \%$ of verb lemmata.

Subjects in Experiment 1 were presented with the uninflected base form of nouns and verbs. The uninflected form is also the usual presentation of a word in isolation. If the frequencies of these presented forms (i.e., the base forms) of the noun and verb stimuli are compared, a substantial frequency difference is evident. Although the noun and verb stimuli of Experiment 1 were selected and matched on the basis of total frequency of occurrence (both the noun stimuli and the verb stimuli had an average frequency of occurrence of 202 per million), the stimuli contrasted in terms of frequency of uninflected forms. In Experiment 1, the uninflected forms of nouns had an average frequency of occurrence of 150 per million whereas the average verb uninflected form frequency was 69 per million. Given these differences, then, it is possible that subjects' response latencies to nouns were faster than those to verbs because the base frequency of nouns is substantially higher than the base frequency of verbs. The differences in RTs to nouns and verbs found in Experiment 1 may simply be due to differences in inflectional structure between nouns and verbs.

To explicitly test this hypothesis, a set of nouns and verbs, equated on frequency of base form, would have to be selected and compared, showing none of the noun-verb differences of Experiment 1. Unfortunately, such an experiment is not possible in English, given the skewed distribution of noun and verb base form frequencies. However, the possible influence of inflectional structure on processing can be further investigated by selecting a single grammatical class and systematically manipulating frequency of uninflected and inflected forms within that class.

\section{EXPERIMENT 2}

A second set of experiments was conducted in order to test whether differences in inflectional structure affect word recognition. The goal of these experiments was to explicitly test whether the frequency of occurrence of individual members of the inflectional paradigm had a systematic effect on response latencies.

In these experiments, only nouns were used. This was primarily because of their unique inflectional character (one uninflected form, one inflected form ${ }^{1}$ ), allowing for a simpler examination of base and inflectional variants. The exclusive use of a single grammatical form class also removed possible confounds due to inherent differences between grammatical classes.

Specifically, Experiment 2 examined the separate contribution of base and inflected forms to overall RT. Stimuli were equated in terms of overall frequency of occurrence but contrasted in terms of frequency of base and inflected forms. Two sets of stimuli were compared in Experiment 2. One set of stimuli had relatively higher frequency singular forms and lower frequency plural 
forms (Condition 1) whereas the other set had relatively higher frequency plural forms and lower frequency singular forms (Condition 2). Total frequency of occurrence was matched between conditions.

Condition 1:

Condition 2:

$$
\mid- \text { sing.-- } \mid- \text { plural-- }
$$

The stimuli were presented to subjects either in the uninflected singular form (Experiment 2A) or in the inflected plural form (Experiment 2B). The subjects' task was to make a lexical decision to the stimuli.

If individual frequency of base or inflected forms has little effect on response latencies, there should not be any difference between conditions, since total frequency is matched. If, however, individual frequency of the morphological forms does have an appreciable effect, significant differences should be found between conditions. In the singular, high-frequency singular forms (Condition 1) should be faster than low-frequency singular forms (Condition 2). In the plural, significant differences should also be found between conditions. The direction of this effect is crucial to discovering whether this difference reflects the influence of the base form frequency (Condition 1 faster than Condition 2) or inflected form frequency (Condition 2 faster than Condition 1). The unique inflectional structure of nouns allows for such a direct comparison in the singular and plural using the same stimuli. Since total frequency of occurrence was equated between conditions, the significant differences in RTs can be attributed to the individual frequency contribution of uninflected or inflected forms.

\section{Experiment 2A}

\section{Method}

Subjects. Sixteen students attending Brown University were paid to participate in the experiment. All were native speakers of English with normal or corrected-to-normal visual acuity.

Materials. Twenty-four words were selected from the Brown corpus (Francis \& Kučera, 1982) and 24 nonwords were constructed (Appendix B). All word stimuli were pure nouns with no occurrences as a verb in English. The noun stimuli were divided into two contrasting groups: high-base/low-plural form nouns and low-base/high-plural form nouns. These groups of stimuli were matched in terms of total frequency of occurrence, with a frequency of 130 per million $(S D=44)$ and 129 per million $(S D=44)$, respectively. However, they contrasted in terms of the relative frequency of their uninflected and inflected forms. For high-base/ low-plural frequency nouns, average frequency of occurrence was 114 per million $(S D=35)$ for uninflected singular forms and 14 per million $(S D=11)$ for plural forms. For low-base/high-plural frequency nouns, average frequency of occurrence was 75 per million $(S D=32)$ for uninflected singular forms and 52 per million $(S D=21)$ for plural forms. High-base/low-plural form nouns had higher frequency singular forms and lower frequency plural forms (e.g., river-rivers) whereas the low-base/high-plural form nouns had lower frequency singular forms and higher frequency plural forms (e.g., window-windows). All stimuli were bisyllabic and were matched for number of letters (6.5 and 6.3 , respectively).

The 24 nonword stimuli were phonotactically acceptable sequences. All were bisyllabic and were matched to the word stimuli in terms of mean number of letters (6.5).
Design and Procedure. The procedure was identical to that described in Experiment 1. The entire experiment lasted approximately $15 \mathrm{~min}$.

\section{Results}

ANOVAs were conducted for subjects $\left(F_{1}\right)$ and items $\left(F_{2}\right)$ for both the RT and error data. All means presented are taken from the subject analyses. No errors or RTs greater than 2 SDs from each subject's mean are included in the analyses. The total number of errors was 11 , representing $1.4 \%$ of all responses.

A one-way ANOVA revealed a main effect of lexical status, with response latencies to words $(627 \mathrm{msec})$ significantly faster than those to nonwords $(662 \mathrm{msec})$ $\left[F_{1}(1,15)=17.81, M S_{\mathrm{e}}=548.30, p<.001 ; F_{2}(1,46)=\right.$ $\left.8.75, M S_{\mathrm{e}}=1,777.39, p=.005\right]$.

A one-way ANOVA for the word stimuli revealed a significant main effect of condition in the subject analy$\operatorname{sis}\left[F_{1}(1,15)=4.59, M S_{\mathrm{e}}=882.73, p=.049 ; F_{2}(1,22)=\right.$ $\left.2.25, M S_{\mathrm{e}}=1,299.18, p=.148\right]$. RTs to high-base frequency nouns $(615 \mathrm{msec})$ were slightly faster than those to low-base frequency nouns $(638 \mathrm{msec})$.

Both subject and item analyses were also conducted for the error data. No significant differences were found either for the word-nonword comparisons or for the highbase-low-base comparisons.

\section{Experiment 2B}

\section{Method}

Subjects. Sixteen new students from the same subject pool as that described in Experiment $2 \mathrm{~A}$ were paid to participate in the experiment.

Materials. The same stimuli as those used in Experiment 2A were used except that all word and nonword stimuli were pluralized by appending the letter $s{ }^{2}$ The same two sets of words were contrasted: the high-base form nouns (which can now be more appropriately labeled "low-plural form nouns") and the low-base form nouns (which can now be more appropriately labeled "high-plural form nouns").

Design and Procedure. The procedure was identical to that described in Experiment 1.

\section{Results}

ANOVAs were conducted for subjects $\left(F_{1}\right)$ and items $\left(F_{2}\right)$ for both the RT and error data. All means presented are taken from the subject analyses. No errors or RTs greater than $2 S D$ s from each subject's mean are included in the analyses. The total number of errors was 24 , representing $3.1 \%$ of all responses.

A one-way ANOVA revealed a main effect of lexical status, with response latencies to words $(653 \mathrm{msec})$ significantly faster than those to nonwords $(696 \mathrm{msec})$ $\left[F_{1}(1,15)=9.01, M S_{\mathrm{e}}=1,594.26, p=.009 ; F_{2}(1,46)=\right.$ $\left.8.39, M S_{\mathrm{e}}=3,000.51, p=.006\right]$.

A one-way ANOVA for the word stimuli revealed a significant main effect of condition $\left[F_{1}(1,15)=5.51\right.$, $M S_{\mathrm{e}}=1,842.46, p=.033 ; F_{2}(1,22)=5.30, M S_{\mathrm{e}}=$ $1,886.53, p=.031]$. Subjects responded significantly more slowly to high-base frequency/low-plural frequency 
nouns $(670 \mathrm{msec})$ than to low-base frequency/highplural frequency nouns $(635 \mathrm{msec})$.

Both subject and item analyses were also conducted for the error data. No significant differences were found either for the word-nonword comparisons or for the highbase/low-plural-low-base/high-plural comparisons.

\section{Combined Results}

A two-way ANOVA (experiment $\times$ condition) was also conducted to compare the results of Experiments $2 \mathrm{~A}$ and 2B. A main effect was found for experiment only in the item analysis $\left[F_{1}(1,30)=.40, M S_{\mathrm{e}}=26,433.88\right.$, $\left.p>.53 ; F_{2}(1,44)=4.48, M S_{\mathrm{e}}=1,592.85, p<.04\right]$. Subjects' responses to the stimuli of Experiment $2 \mathrm{~A}$ $(627 \mathrm{msec})$, in which the singular form of the noun was presented, were slightly faster than the RTs to the same stimuli in Experiment 2B ( $653 \mathrm{msec})$, in which the plural form of those nouns was presented. In addition, there was no significant main effect of condition across both experiments $(F \mathrm{~s}<1)$. High-base frequency/low-plural frequency nouns were not facilitated more than were low-base frequency/high-plural frequency nouns across both singular and plural forms.

However, there was a significant experiment $\times$ condition interaction in both the subject and item analyses $\left[F_{1}(1,30)=9.92, M S_{\mathrm{e}}=1,362.60, p<.004 ; F_{2}(1,44)=\right.$ 7.46, $\left.M S_{\mathrm{e}}=1,592.85, p<.009\right]$. When the stimuli were presented in the singular form, responses to high-base form nouns were faster than those to low-base form nouns and, when these same stimuli were presented in the plural form, the opposite pattern occurred (Figure 2). That is, in the plural, responses to the high-base form nouns were slower than those to the low-base form nouns. The frequency of the presented form appears to be the main determinant of response latencies.

\section{Discussion}

The basic question addressed by Experiment 2 was whether differences in inflectional structure are effective

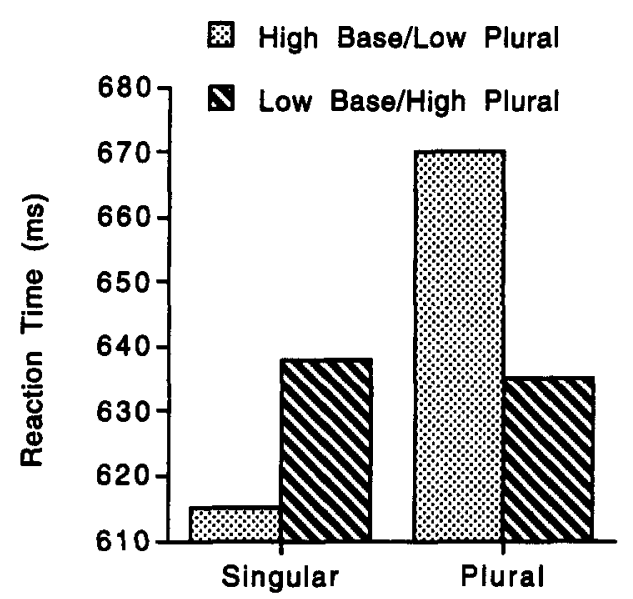

Figure 2. Mean lexical decision times (in milliseconds) for highbase/low-plural frequency nouns and low-base/high-plural frequency nouns presented in the singular (Experiment $2 \mathrm{~A}$ ) and plural (Experiment 2B). in word recognition processes. In Experiment 2, two sets of nouns were used that were equated in terms of overall frequency of occurrence but that contrasted in terms of the proportion of uninflected to inflected forms. Highbase/low-plural frequency nouns were contrasted to lowbase/high-plural frequency nouns. These stimuli were then presented to subjects in either the singular (Experiment $2 \mathrm{~A}$ ) or the plural (Experiment 2B).

Both Experiments $2 \mathrm{~A}$ and $2 \mathrm{~B}$ showed significant processing differences between high-base/low-plural frequency nouns compared with low-base/high-plural frequency nouns. These differences, however, are in opposite directions. When these nouns were presented in the singular (Experiment 2A), a sizable difference was observed, with RTs to high-base/low-plural frequency nouns $(615 \mathrm{msec})$ faster than those to low-base/high-plural frequency nouns $(638 \mathrm{msec})$. When the same stimuli were presented in the plural (Experiment 2B), a sizable difference was also observed except that responses to the high-base/low-plural frequency stimuli $(670 \mathrm{msec})$ were significantly slower than those to the low-base/highplural frequency stimuli $(635 \mathrm{msec})$.

The combined results of Experiments $2 \mathrm{~A}$ and $2 \mathrm{~B}$ show a significant interaction. Singular nouns are faster when the proportion of the base form frequency is high than when it is low, whereas plural nouns are faster when the proportion of the plural form frequency is high than when it is low. It seems that the frequency of the presented form substantially influences reaction time. Although the same stimuli were used in the two experiments (uninflected nouns in Experiment $2 \mathrm{~A}$ and inflected nouns in $2 B$ ) and the stimuli were matched for total frequency of occurrence, these data show a significant surface frequency effect. These results suggest that the frequency of each of the regular inflectional variants individually affects response latencies.

\section{EXPERIMENT 3}

Experiment 3 assessed the separate contribution of total frequency of occurrence. Since total frequency of occurrence was equated in Experiment 2, its contribution could not be independently evaluated. The goal of Experiment 3 was to gauge the relative importance of total frequency as an independent contributor to overall reaction time.

Sereno and Jongman $(1991,1992)$ conducted preliminary analyses to investigate the influence of total frequency of occurrence on response latency. In a post hoc analysis of published data (Whaley, 1978), Sereno and Jongman found that combined frequency seemed to have little effect on RTs to uninflected stimuli. The analyzed Whaley data consisted of RTs for 32 subjects responding to 32 items. All stimuli were presented in the singular, uninflected form. Sereno and Jongman reported no significant differences in reaction time between stimuli that were equated in singular frequency (94 per million and 96 per million, respectively) but that contrasted in total frequency (173 per million and 114 per million, respectively). That is, the high total frequency stimuli $(558 \mathrm{msec})$ were not significantly differ- 
ent from the low total frequency stimuli $(551 \mathrm{msec})$, suggesting that uninflected base form frequency was the more substantial determinant of response latency.

Experiment 3 was an explicit and systematic evaluation of the contribution of cumulative inflectional frequency on RTs. In Experiment 3, stimuli were equated for frequency of uninflected form and contrasted in terms of total frequency.

$$
\begin{array}{ll|}
\text { Condition 1: } & \mid- \text { sing.- } \mid- \text { plural- }-\mid \\
\text { Condition 2: } & \mid- \text { sing. }-\mid \text { plural }-\mid
\end{array}
$$

The stimuli were presented to subjects either in the uninflected singular form (Experiment 3A) or in the inflected plural form (Experiment 3B). Subjects' task was to make a lexical decision to the stimuli.

If total frequency contributes little, as was suggested by the preliminary analysis, no significant differences should be found between conditions in the singular (Condition 1 = Condition 2), since base frequency is equated. In the plural, however, significant differences may be expected to be found between conditions, with responses to high-frequency plural forms (Condition 1) being faster than those to low-frequency plural forms (Condition 2). If, however, total frequency does have a significant contribution to reaction time, then significant differences are expected in both the singular and the plural, with Condition 1 always being faster than Condition 2. Experiments 3A and 3B, then, directly assessed the contribution of total frequency to RT.

\section{Experiment 3A}

\section{Method}

Subjects. Thirty-four students attending Cornell University were paid for their participation in the experiment. All were native speakers of English with normal or corrected-to-normal visual acuity.

Materials. Forty words were selected from the Brown corpus (Francis \& Kučera, 1982) and 40 nonwords were constructed (Appendix C). All word stimuli were pure nouns with no occurrences as a verb in English. The noun stimuli were divided into two contrasting groups: equal-base/high-plural nouns and equal-base/lowplural frequency nouns. These groups of stimuli were matched in terms of uninflected (base form) frequency but contrasted in terms of their total frequency of occurrence, so that the equal-base/lowplural form nouns had lower total frequency of occurrence (e.g., desk-desks) whereas the equal-base/high-plural form nouns had higher total frequency of occurrence (e.g., tree-trees).

The equal-base/high-plural nouns and equal-base/low-plural nouns contrasted in terms of total frequency, with a mean frequency per million of $218(S D=131)$ and $106(S D=57)$, respectively. Although these stimuli were matched for frequency of occurrence of uninflected forms, with a mean frequency per million of 93 $(S D=63)$ and $98(S D=55)$, respectively, the stimuli contrasted in terms of frequency of occurrence of inflected forms, with a mean frequency per million of $121(S D=77)$ and $7(S D=4)$, respectively. Stimuli were matched for mean number of letters (1.6 and 1.7 , respectively) and mean number of syllables (5.4 and 5.4, respectively). For each group, one of the bisyllabic stimuli was backstressed and all the other bisyllabic stimuli were forestressed.

The 40 nonword stimuli were phonotactically acceptable sequences and were matched to the word stimuli in terms of mean number of letters (5.3) and mean number of syllables (1.6).

Design and Procedure. All subjects were tested in groups of four. Subjects were instructed to make a lexical decision to each stimulus. Following instructions, subjects were given a set of 12 practice items to familiarize them with the procedure. The practice items were not used in the test.

Stimulus timing was controlled by a Swan 80386 computer and stimuli were presented on a Magnavox video monitor (Model 7BM749). Stimuli in lowercase letters appeared in the center of the screen for $500 \mathrm{msec}$. Stimuli were presented at a fixed rate, with an SOA of 1.5 sec. Reaction time was measured from the onset of the stimulus until a response was made. The entire experiment lasted approximately $15 \mathrm{~min}$.

\section{Results}

ANOVAs were conducted for subjects $\left(F_{1}\right)$ and items $\left(F_{2}\right)$ for both the RT and error data. All means presented are taken from the subject analyses. No errors or RTs greater than $2 S D$ s from each subject's mean are included in the analyses. The total number of errors was 172 , representing $6.3 \%$ of all responses.

A one-way ANOVA revealed a main effect of lexical status, with response latencies to words $(559 \mathrm{msec}) \mathrm{sig}$ nificantly faster than those to nonwords $(607 \mathrm{msec})$ $\left[F_{1}(1,33)=50.31, M S_{\mathrm{e}}=776.89, p<.001 ; F_{2}(1,78)=\right.$ $\left.77.37, M S_{\mathrm{e}}=677.12, p<.001\right]$

A one-way ANOVA for the word stimuli did not reveal a significant main effect of condition $(F \mathbf{s}<1)$. Equal-base/high-plural frequency nouns $(560 \mathrm{msec})$ were not significantly different from equal-base/lowplural frequency nouns $(558 \mathrm{msec})$.

Both subject and item analyses were also conducted for the error data. No significant differences were found for the equal-base/high-plural-equal-base/low-plural comparisons.

\section{Experiment 3B}

\section{Method}

Subjects. Thirty-four new students from the same subject pool as that described in Experiment $3 \mathrm{~A}$ were paid to participate in the experiment.

Materials. The same stimuli as those used in Experiment 3A were used except that all word and nonword stimuli were pluralized by appending an $s$. The same two sets of words were contrasted: the equal-base/high-plural form nouns and the equal-base/low-plural form nouns.

Design and Procedure. The procedure was identical to that described in Experiment $3 \mathrm{~A}$.

\section{Results}

ANOVAs were conducted for subjects $\left(F_{1}\right)$ and items $\left(F_{2}\right)$ for both the RT and error data. All means presented are taken from the subject analyses. No errors or RTs greater than $2 S D$ s from each subject's mean are included in the analyses. The total number of errors was 151 , representing $5.6 \%$ of all responses.

A one-way ANOVA revealed a main effect of lexical status, with response latencies to words $(585 \mathrm{msec})$ significantly faster than those to nonwords $(619 \mathrm{msec})$ $\left[F_{1}(1,33)=42.03, M S_{\mathrm{e}}=486.72, p<.001 ; F_{2}(1,78)=\right.$ $\left.40.21, M S_{\mathrm{e}}=655.13, p<.001\right]$.

A one-way ANOVA for the word stimuli revealed a significant main effect of condition for subjects and a strong trend in the item analysis $\left[F_{1}(1,33)=8.50, M S_{\mathrm{e}}=\right.$ 
$214.50, p=.006 ; F_{2}(1,38)=3.38, M S_{\mathrm{e}}=333.45, p=$ $.074]$. Subjects responded faster to equal-base/highplural frequency nouns $(579 \mathrm{msec})$ than to equal-base/ low-plural frequency nouns $(590 \mathrm{msec})$.

Both subject and item analyses were also conducted for the error data. No significant differences were found for the equal-base/high-plural-equal-base/low-plural comparisons.

\section{Combined Analysis}

A two-way ANOVA (experiment $\times$ condition) was also conducted to compare the results of Experiments $3 \mathrm{~A}$ and $3 \mathrm{~B}$. A significant main effect was found for experiment in the item analysis and a strong trend was observed in the subject analysis $\left[F_{\mathrm{f}}(1,66)=3.63, M S_{\mathrm{e}}=6,278.19\right.$, $\left.p=.061 ; F_{2}(1,76)=41.36, M S_{\mathrm{e}}=321.64, p<.001\right]$. RTs to the stimuli of Experiment 3 A $(559 \mathrm{msec})$, in which the singular nouns were presented, were faster than RTs to the same stimuli in Experiment 3B $(585 \mathrm{msec})$, in which the plural form of those nouns was presented. There was no significant main effect of condition across both experiments $\left[F_{1}(1,66)=2.56, M S_{\mathrm{e}}=258.96, p=\right.$ $\left..114 ; F_{2}(1,76)=1.36, M S_{\mathrm{e}}=321.64, p=.248\right]$. RTs to equal-base/high-plural frequency nouns $(570 \mathrm{msec})$ were not faster than those to equal-base/low-plural frequency nouns $(574 \mathrm{msec})$ across both singular and plural forms.

However, there was a significant experiment $\times$ condition interaction in the subject analysis, but this effect did not reach significance in the item analysis $\left[F_{1}(1,66)=\right.$ $4.62, M S_{\mathrm{e}}=258.96, p=.035 ; F_{2}(1,76)=2.20, M S_{\mathrm{e}}=$ $321.64, p=.142]$. In general, the two experimental conditions behaved slightly differently depending on whether the items were presented in the singular or plural (Figure 3). That is, when the stimuli were presented in the singular form, RTs to equal-base/high-plural nouns were similar to those to the equal-base/low-plural nouns, but when these same stimuli were presented in the plural

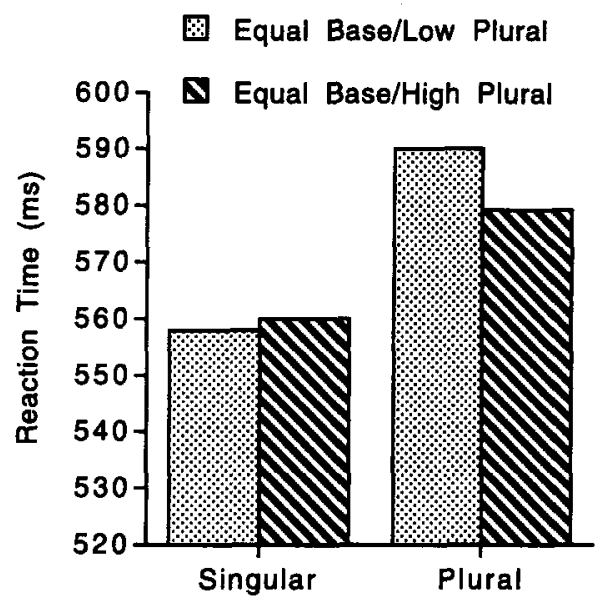

Figure 3. Mean lexical decision times (in milliseconds) for equal-base/low-plural frequency nouns and equal-base/highplural frequency nouns presented in the singular (Experiment $3 A$ ) and plural (Experiment 3B). form, RTs to equal-base/high-plural nouns were faster than those to equal-base/low-plural nouns.

\section{Discussion}

Experiment 3 examined whether differences in total frequency are effective in word recognition processes. In Experiment 3, two sets of nouns were used, equated in terms of frequency of occurrence of uninflected forms but contrasting in terms of total frequency. Equal-base/highplural frequency nouns were contrasted to equal-base/lowplural frequency nouns. These stimuli were then presented to subjects in either the singular (Experiment $3 \mathrm{~A}$ ) or the plural (Experiment 3B).

Experiment $3 \mathrm{a}$, presenting stimuli in the singular, showed no significant processing differences between equal-base/high-plural frequency nouns $(560 \mathrm{msec})$ compared with equal-base/low-plural frequency nouns (558 $\mathrm{msec})$. However, a significant difference did appear when stimuli were presented in the plural (Experiment 3B), with responses to equal-base/high-plural frequency nouns $(579 \mathrm{msec})$ being faster than those to equal-base/low-plural frequency nouns $(590 \mathrm{msec})$.

The combined results of Experiments $3 \mathrm{~A}$ and $3 \mathrm{~B}$ showed a significant interaction. RTs to equal-base/highplural frequency nouns and equal-base/low-plural frequency nouns were different depending on whether they were presented in the singular or plural. For uninflected nouns, there was no difference between equal-base/highplural frequency nouns and equal-base/low-plural frequency nouns. For these stimuli, singular frequency is equated whereas total frequency differences are substantial. This does not seem to be simply a lack of observing an effect, since, in the plural, a significant difference was found for these same stimuli. In this case, the substantial frequency differences in the plural resulted in significant processing differences. It seems that the frequency of the presented form substantially influences RT, regardless of total frequency of occurrence.

The finding that total frequency contributes little to response latencies in uninflected or inflected nouns suggests that the frequency of each of the uninflected and inflected variants individually affects response latencies. Again, there appears to be a substantial surface frequency effect for English nouns that follow a regular pattern of pluralization.

\section{GENERAL DISCUSSION}

The present research investigated the organization of lexical representations in memory by systematically varying inflectional morphological structure in English. In a series of lexical decision experiments, the frequency of occurrence of inflectional variants was manipulated so that the individual contribution of uninflected and inflected form frequency as well as the contribution of cumulative frequency could be assessed. Further, only nouns were used as stimuli because variations in inflectional structure can be tightly controlled. 
In Experiment 1, differences in grammatical class were investigated. The latencies to the uninflected base form of nouns were significantly shorter than those of verbs. An additional analysis indicated this was not due to inherent differences in stress placement between nouns and verbs. We suggest the contrasting inflectional structure of nouns and verbs as a possible explanation for the grammatical category effect. An analysis of English using data from the Brown corpus (Francis \& Kučera, 1982) revealed that the uninflected base (citation) forms of nouns and verbs differ greatly in frequency of usage. For English, the uninflected base form of nouns constitutes $73.6 \%$ of the total frequency of nouns whereas the uninflected base form of verbs constitutes only $29.3 \%$ of total verb frequency (Sereno \& Jongman, 1992). Differences between nouns and verbs found in Experiment 1, therefore, may simply be the result of the differential distribution of word forms belonging to a lemma, with the facilitation of nouns over verbs being attributed to the more substantial contribution of base frequency for nouns. Specifically, the frequency of the presented form of nouns (i.e., their singular or base form) is substantially higher than the frequency of the presented form of verbs (i.e., their infinitival form), thereby resulting in a substantial RT difference between these two different grammatical classes.

Experiments 2 and 3 addressed how differences in inflectional structure affect word recognition processes. Only noun stimuli were used in order to systematically control for unpredictable variations in inflectional structure. In these experiments, frequency of occurrence of the individual forms of an inflectional paradigm was manipulated to precisely establish the locus of the effect. Stimuli were then presented either in the singular or in the plural to determine which form drives response latency.

A set of nouns matched in total frequency but contrasting in the frequency of their uninflected and inflected forms was presented to subjects both in the singular (Experiment 2A) and the plural (Experiment 2B). The results of Experiments $2 \mathrm{~A}$ and $2 \mathrm{~B}$ show that the surface frequency of the item that is presented has a strong effect on response latency. In the singular, responses to nouns with high-singular forms are faster than those to nouns with low-singular forms, whereas in the plural, responses to the same nouns with high-singular forms (low-plural forms) are slower than those to nouns with low-singular forms (high-plural forms). For nouns matched in overall frequency of occurrence, there is a strikingly different result depending on whether stimuli are presented in the singular or in the plural. A reversal of the response latencies to high- and low-base form nouns occurs under uninflected and inflected presentations.

Although a highly significant interaction was present, the effect between conditions (high-singular/low-plural forms and low-singular/high-plural forms) appears to have been stronger for inflected forms. It is possible that total frequency of occurrence also plays a contributing role to response latency differences. That is, when stimuli are uninflected, total frequency, which was matched across conditions, may have had a tendency to neutralize the differences.

Experiment 3 investigated this possibility by assessing the separate contribution of total frequency of occurrence. In this experiment, stimuli were equated for frequency of uninflected forms and varied in total frequency (and, therefore, also in frequency of inflected plural forms). The stimuli were presented to subjects both in the singular (Experiment $3 \mathrm{~A}$ ) and in the plural (Experiment 3B). The results of Experiments $3 \mathrm{~A}$ and $3 \mathrm{~B}$ also show that surface frequency is a strong determinant of response latency. In the singular, nouns matched in frequency of uninflected forms have comparable RTs, despite substantial differences in overall frequency. However, for the same nouns in the plural, a significant difference between conditions is observed. These RT differences are in accord with the frequency of occurrence difference for these plural stimuli.

In sum, the present series of experiments examined the comprehension of morphological relations by systematically varying uninflected and inflected forms. The results from these RT experiments suggest that the processing of regularly inflected nouns in English (singulars and plurals) behaves according to surface frequency of occurrence.

How do these results compare with previous data? Recall that Taft (1979) in English and Burani et al. (1984) in Italian observed both surface frequency and cumulative frequency effects. However, the methodological structure of these experiments was not ideal. Burani et al. solely tested inflected stimuli and examined only verbs, and although Taft presented both uninflected and inflected stimuli, his comparisons included grammatically ambiguous stimuli (i.e., words used both as nouns and verbs). Thus Taft, for example, contrasted inflected verb stimuli, matching in both inflected and uninflected verb frequency and differing only in noun frequency. Such comparisons introduce an additional variable, grammatical class, and make it difficult to assess the locus of the frequency effects. Moreover, for Taft, stimuli used for comparisons of uninflected forms were different from those used to make the contrasts for inflected forms. This design is not optimal, a concern raised also by $\mathrm{Bu}-$ rani et al. In one of their experiments, Burani et al. attempted to control for stimulus structure by contrasting stimuli with the same root morpheme but different surface frequencies. In this specific comparison, the data showed significant surface frequency effects. More recently, Katz et al. (1991) also attempted to control for stimulus selection by contrasting the frequency of stem to inflected forms for the same stimuli. Presenting both uninflected and inflected verb stimuli to subjects, they found that surface frequency seems to be a better predictor of response latencies than total frequency (although the results are somewhat confusing for present participle forms). It should be noted, however, that Katz et al. did not systematically manipulate uninflected, inflected, or total frequency of occurrence for the stimuli but instead regressed RT on log frequency of occurrence 
to compare stimuli from the same inflectional paradigm. Although these previous experimental findings offer the suggestion of a substantial role for surface frequency in word recognition, they also bring out the need for more strict methodological design.

A unique aspect of the present series of experiments is that the same set of stimuli were tested in the singular and plural, allowing a direct comparison of the contribution of frequency of occurrence of uninflected and inflected forms to reaction time. With this design, stimulus selection cannot be a confounding factor. Furthermore, the present series of experiments makes exclusive use of noun inflectional paradigms. Although most previous research concentrated on verbal morphology, the inflectional structure of verbs is more complex than that of nouns, since, in English, five inflectional verb variants are possible (infinitive, third-person singular, present participle, past tense, and past participle). Finally, in the present experiments, only a single grammatical class of noun was used; that is, these stimuli have no (possibly confounding) occurrences as other parts of speech. Given these three experimental manipulations, differences in reaction time between groups of stimuli cannot be attributed to differences in structure of the stimuli.

Recently, both Marslen-Wilson et al. (1994) and McQueen and Cutler (in press) cited a number of linguistic and psychological factors that may account for the lack of consensus in current research on morphological issues. These include issues of access versus representation, language-specific differences, the effect of modality (auditory vs. visual), and the linguistic characterization of the morphologically complex item. The present series of experiments examining pluralization in English attempted to address these factors by eliminating a number of previously uncontrolled linguistic variables.

The results of experiments examining morphological structure have typically been interpreted in terms of a basic distinction between symbolic, rule-based accounts and network solutions. In general, two contrasting approaches have been delineated - dual-mechanism models and single-mechanism models. Dual-mechanism models posit a dissociation between regular and irregular morphological items (see, e.g., Kim, Pinker, Prince, \& Prasada, 1991; Marcus et al., 1992; Pinker \& Prince, 1994; Prasada \& Pinker, 1993). In English, there are fully predictable processes that allow a speaker to inflect an unlimited number of nouns (e.g., Chomsky \& Halle, 1968; Taft, 1988; Taft \& Forster, 1975). This is illustrated most clearly in the developmental literature by the formation of regular plural forms from uninflected nonwords (e.g., wug-wugs; Berko, 1958). Under a rulebased approach, predictable morphological information (e.g., add -s, add -ed) need not be redundantly represented. Rather, there is a fully predictable rule that concatenates the affix to the stem to account for the productivity of the regular forms. Irregular past tense verbs, such as ate or sang, on the other hand, are unpredictable and, therefore, each item must be individually stored. In such dual-mechanism or hybrid models, regular inflec- tional forms are computed by rule whereas irregular forms are represented independently in an associative network. Two different mechanisms, with possibly distinct anatomical loci, are posited for generating regular and irregular forms (Pinker, 1991).

Alternatively, connectionist, associationist, or network theories claim that both regular and irregular forms are computed by a single mechanism (e.g., Bybee, 1988, 1995; Daugherty \& Seidenberg, 1994; Plunkett \& Marchman, 1993; Rumelhart \& McClelland, 1986, 1987). In a connectionist model, inputs representing the orthographic or auditory pattern of the stem are linked to outputs representing the orthographic or auditory pattern of the inflected form. A single network handles both the regulars and irregulars. Connectionist accounts suggest that regular forms, like irregulars, can be represented in the same network, and that their productivity is directly related to the number of lexical items displaying that same pattern. In this manner, the network generates regular inflectional patterns while at the same time accounting for patterns within irregular forms.

The present series of word recognition experiments lends initial support to a unitary associative system for processing regular inflected nouns in English. In these experiments, differences in response latencies are predicted by the frequency of the surface form, whether uninflected or inflected. This suggests that morphologically regular nouns in English may not be derived by rule from a single, uninflected lexical entry. Token frequency is relevant in the processing of regular inflected forms. These preliminary results do not support the existence of two separate systems - a regular system that is rulebased and computes inflectional forms by a predictable rule that concatenates a plural suffix with a stem, and an irregular system that independently represents uninflected stems mapped onto irregular inflectional forms. Rather, regular inflectional forms behave similarly to irregular forms, with respect to token frequency. Even for a process as productive as number marking in English, each inflectional form seems to have its own particular frequency, and this frequency plays an important role in lexical processes. The individual members of the regular inflectional paradigm appear to be represented separately, a position more akin to the connectionist or network models of morphological organization.

In the discussion of rule-based versus associationist models of lexical organization, the traditional rationale has been the efficiency in storage capacity - namely, that it is more efficient to derive morphologically complex items by rule, thus minimizing storage in memory for those derived items. But it is also possible to look at the problem in terms of processing efficiency. One could argue that it is more efficient to store every piece of information separately, allowing direct access to all forms, without having to invoke the additional operation of a rule. The present series of experiments suggests that, at least for productive inflectional paradigms involving nouns in English, morphological processing is accomplished by individually representing all morphological 
variants and depending on efficient processing procedures. Processing procedures are optimal, whereas storage limitations do not appear to be a critical factor.

The present results are compatible with an associative network model of lexical organization for processing regular inflection of nouns in English. Understanding the morphological constraints on lexical representations is crucial to the refinement of psychologically and linguistically valid theories of lexical organization.

\section{REFERENCES}

Behrend, D. (1990). The development of verb concepts: Children's use of verbs to label familiar and novel events. Child Development, 61, 681-696.

Berko, J. (1958). The child's learning of English morphology. Word, $14,150-177$.

BradeEy, D. (1978). Computational distinctions of vocabulary type. Unpublished doctoral dissertation, MIT.

Burani, C., Salmaso, D., \& Caramazza, A. (1984). Morphological structure and lexical access. Visible Language, 18, 342-352.

BUTTERWORTH, B. (1983). Lexical representation. In B. Butterworth (Ed.), Language production (Vol. 2, pp. 257-294). London: Academic Press.

ByBEE, J. (1988). Morphology as lexical organization. In M. Hammond \& M. Noonan (Eds.), Theoretical morphology (pp. 119-141). New York: Academic Press.

B үвее, J. (1995). Regular morphology and the lexicon. Language \& Cognitive Processes, 10, 425-455.

Caramazza, A., \& Hillis, A. (1991). Lexical organization of nouns and verbs in the brain. Nature, 349, 788-790.

Caramazza, A., Laudanna, A., \& Romani, C. (1988). Lexical access and inflectional morphology. Cognition, 28, 297-332.

Сномsкy, N., \& Halle, M. (1968). Sound pattern of English. New York: Harper \& Row.

Clark, H., \& ClaRk, E. (1977). Psychology and language: An introduction to psycholinguistics. New York: Harcourt Brace.

Daugherty, K., \& Seidenberg, M. (1994). Beyond rules and exceptions: A connectionist approach to inflectional morphology. In S. Lima, R. Corrigan, \& G. Iverson (Eds.), The reality of linguistic rules (pp. 353-388). Philadelphia: John Benjamins.

Feldman, L. (1995). Morphological aspects of language processing. Hillsdale, NJ: Erlbaum.

Fischler, I., \& GoODMAN, G. (1978). Latency of associative activation in memory. Journal of Experimental Psychology: Human Perception \& Performance, 4, 455-470.

Forster, K., \& Chambers. S. (1973). Lexical access and naming time Journal of Verbal Learning \& Verbal Behavior, 12, 627-635.

FRANCIS, N., \& KUČERA, H. (1982). Frequency analysis of English usage: Lexicon and grammar. Boston: Houghton Mifflin.

Frauenfelder, U., \& Schreuder, R. (1992). Constraining psycholinguistic models of morphological processing and representation: The role of productivity. In G. Booij \& J. van Marle (Eds.), Yearbook of morphology 1991 (pp. 165-183). Dordrecht: Kluwer.

FRIEDERICI, A. (1985). Levels of processing and vocabulary types: Evidence from on-line comprehension in normals and agrammatics. Cognition, 19, 133-166.

GENTNER, D. (1978). On relational meaning: The acquisition of verb meaning. Child Development, 49, 988-998.

GENTNER, D. (1981). Some interesting differences between nouns and verbs. Cognition \& Brain Theory, 4, 161-178.

GENTNER, D. (1982). Why nouns are learned before verbs: Linguistic relativity vs. natural partitioning. In S. Kuczaj (Ed.), Language development: Language, culture, and cognition (pp. 301-335). Hillsdale, NJ: Erlbaum.

Gordon, B., \& Caramazza, A. (1982). Lexical decision for open- and closed-class words: Failure to replicate differential frequency sensitivity. Brain \& Language, 15, 143-160.
Gordon, B., \& Caramazza, A. (1985). Lexical access and frequency sensitivity: Frequency saturation and open/closed class equivalence. Cognition, 21, 95-115.

Graesser, A., Hopkinson, P., \& Schmid, C. (1987). Differences in interconcept organization between nouns and verbs. Journal of Memory \& Language, 26, 242-253.

HeNDERSON, L. (1985). Toward a psychology of morphemes. In A. W. Ellis (Ed.), Progress in the psychology of language (Vol. 1, pp. 15-72). Hillsdale: Erlbaum.

Hocketr, C. (1968). The state of the art. The Hague: Mouton.

HutTENLOCHER, J., \& LUI, F. (1979). The semantic organization of some simple nouns and verbs. Journal of Verbal Learning \& Verbal Behavior, 18, 141-162.

Katz, L., Rexer, K., \& Lukatela, G. (1991). The processing of inflected words. Psychological Research, 53, 25-32.

KEAN, M.-L. (1977). The linguistic interpretation of aphasic syndromes: Agrammatism in Broca's aphasia, an example. Cognition, 5, 9-46.

Kelliher, S., \& Henderson, L. (1990). Morphologically based frequency effects in the recognition of irregularly inflected verbs. British Journal of Psychology, 81, 527-539.

KeLly, M. H., \& Bock, J. K. (1988). Stress in time. Journal of Experimental Psychology: Human Perception \& Performance, 14, 389-403.

Kim, J., Pinker, S., Prince, A., \& Prasada, S. (1991). Why no mere mortal has ever flown out to center field. Cognitive Science, 15, 173-218.

Lukatela, G., Carello, C., \& Turvey, M. T. (1987). Lexical representation of regular and irregular inflected nouns. Language $\&$ Cognitive Processes, 2, 1-17.

Lukatela, G., GligoriJević, B., Kostić, A., \& Turvey, M. T. (1980) Representation of inflected nouns in the internal lexicon. Memory \& Cognition, 8, 415-423.

Lukatela, G., Mandić, Z., Gligorijević, B., Kostić, A., Savić, M., \& TURVEY, M. T. (1978). Lexical decision and inflected nouns. Language \& Speech, 21, 166-173.

Manelis, L., \& Tharp, D. (1977). The processing of affixed words. Memory \& Cognition, 5, 690-695.

Marcus, G., Pinker, S., Ullman, M., Hollander, J., Rosen, T., \& $\mathrm{XU}, \mathrm{F} .(1992)$. Overregularization in language acquisition. Monographs of the Society for Research in Child Development, 57(4, Serial No. 228).

Marslen-Wilson, W., Tyler, L., WaKsler, S., \& Older, L. (1994). Morphology and meaning in the English mental lexicon. Psychological Review, 101, 3-33.

MatThews, P. (1974). Morphology. Cambridge: Cambridge University Press.

MCQueEn, J. M., \& CuTler, A. (in press). Morphology in word recognition. In A. M. Zwicky \& A. Spencer (Eds.), The handbook of morphology. Oxford: Blackwell.

Mertus, J. (1989). BLISS manual. Providence, RI: Brown University.

MeYer, D., \& SChVANEVELdT, R. (1971). Facilitation in recognizing pairs of words: Evidence of a dependence between retrieval operations. Journal of Experimental Psychology, 90, 227-234.

Miceli, G., Silveri, M., Villa, G., \& Caramazza, A. (1984). On the basis for the agrammatic's difficulty in producing main verbs. Cortex, 20, 207-220.

Pinker, S. (1991). Rules of language. Science, 253, 530-535.

Pinker, S., \& Prince, A. (1994). Regular and irregular morphology and the psychological status of rules of grammar. In S. Lima, R. Corrigan, \& G. Iverson (Eds.), The reality of linguistic rules (pp. 321-351). Philadelphia: John Benjamins.

Plunkett, K., \& Marchman, V. (1993). From rote learning to system building: Acquiring verb morphology in children and connectionist nets. Cognition, 48, 21-69

Prasada, S., \& PINKer, S. (1993). Generalisation of regular and irregular morphological patterns. Language \& Cognitive Processes, 8, 1-56.

Rubenstein, H., Lewis, S.. \& Rubenstein, M. (1971). Evidence for phonemic recoding in visual word recognition. Journal of Verbal Learning \& Verbal Behavior, 10, 645-657.

RumelharT, D. E., \& MCClelland, J. L. (1986). On learning the past tenses of English verbs. In J. L. McClelland, D. E. Rumelhart, \& the PDP Research Group (Eds.), Parallel distributed processing: Explo- 
rations in the microstructure of cognition (Vol. 2, pp. 216-271). Cambridge, MA: MIT Press.

RumelHaRT, D., \& MCClelland, J. (1987). Learning the past tenses of English verbs: Implicit rules or parallel distributed processing. In B. MacWhinney (Ed.), Mechanisms of language acquisition (pp. 195-248). Hillsdale, NJ: Erlbaum.

SANDRA, D. (1994). The morphology of the mental lexicon: Internal word structure viewed from a psycholinguistic perspective. Language \& Cognitive Processes, 9, 227-269.

SAPIR, E. (1944). Grading: A study in semantics. Philosophy of Science, 11, 93-116.

Schreuder, R., \& BaAyen, R. H. (1994). Prefix stripping re-revisited. Journal of Memory \& Language, 33, 357-375.

SChriefers, H., Friederici, A., \& Graetz, P. ( 1992). Inflectional and derivational morphology in the mental lexicon: Symmetries and asymmetries in repetition priming. Quarterly Journal of Experimental Psychology, 44A, 373-390.

SERENO, J.A. (1986). Stress pattern differentiation of form class in English. Journal of the Acoustical Society of America, 79, S36.

SERENO, J. A. (1991). Graphemic, associative, and syntactic priming effects at a brief stimulus onset asynchrony in lexical decision and naming. Journal of Experimental Psychology: Learning, Memory, \& Cognition, 17, 459-477.

Sereno, J. A., \& Jongman, A. (1990). Phonological and form class relations in the lexicon. Journal of Psycholinguistic Research, 19, 387-404

Sereno, J. A., \& Jongman, A. (1991, January). Inflectional morphology in the mental lexicon. Paper presented at the annual meeting of the Linguistic Society of America, Chicago.

Sereno, J. A., \& Jongman, A. (1992, March). The processing of inflectional morphology in English. Poster presented at the fifth annual CUNY Conference on Human Sentence Processing, New York

Sereno, J. A., \& Jongman, A. (1995). Acoustic correlates of grammatical class. Language \& Speech, 38, 57-76.

Sereno, J. A., Slack, E., \& Jongman, A. (1996, November). Hemispheric differences in grammatical class. Paper presented at the annual meeting of the Psychonomic Society, Chicago.

StanNers, R., JastrzembSki, J., \& Westbrook, A. (1975). Frequency and visual quality in a word-nonword classification task. Journal of Verbal Learning \& Verbal Behavior, 14, 259-264.

TAFT, M. (1979). Recognition of affixed words and the word frequency effect. Memory \& Cognition, 7, 263-272.

TAFT, M. (1985). The decoding of words in lexical access: A review of the morphographic approach. In D. Besner, T. Walker, \& G. Mackinnon (Eds.), Reading research: Advances in theory and practice (Vol. 5 , pp. 83-124). New York: Academic Press.

TAFT, M. (1988). A morphological decomposition model of lexical representation. Linguistics, 26, 657-667.

TAFT, M. (1991). Reading and the mental lexicon. Hove, U. K.: Erlbaum.

TAFT, M., \& ForSTER, K. I. (1975). Lexical storage and retrieval of prefixed words. Journal of Verbal Learning \& Verbal Behavior, 14 630-647.

WARREN, R. (1977). Time and the spread of activation in memory. Jour nal of Experimental Psychology: Human Learning \& Memory, 3 , 458-466.

WhaLEY, C. P. (1978). Word-nonword classification time. Journal of Verbal Learning \& Verbal Behavior, 17, 143-154

ZINGESER, L., \& BERNDT, R. (1988), Grammatical class and context effects in a case of pure anomia: Implications for models of language production. Cognitive Neuropsychology, 5, 473-516.

ZURIF, E. (1980). Language mechanisms: A neuropsychological perspective. American Scientist, 10, 132-144.
ZWITSERLOOD, P. (1994). The role of semantic transparency in the processing and representation of Dutch compounds. Language \& Cognitive Processes, 9, 341-368.

\section{NOTES}

1. Since possessive nouns constitute less than $1 \%$ of all noun occurrences, their contribution to the inflectional structure of nouns is minimal.

2. Two orthographically irregular plurals (county-counties, lady-ladies) were included, one high-base/low-plural noun and one low-base/high-plural noun.

\section{APPENDIX A}

\begin{tabular}{llll}
\hline Noun & Verb & \multicolumn{2}{c}{ Nonwords } \\
\hline church & bring & trin & smed \\
door & appear & drig & kade \\
street & believe & zear & plest \\
moment & remain & preak & chall \\
office & serve & creaf & driss \\
person & grow & glant & grom \\
method & happen & visp & zill \\
effort & include & zimp & sarb \\
music & send & fint & troz \\
story & suggest & glab & pish \\
food & seek & blung & plark \\
nature & prepare & corple & pasil \\
husband & prove & sorneg & shiger \\
tree & teach & rensor & glurshet \\
hotel & fail & wootis & terwin \\
freedom & join & biffle & oastrak \\
truth & prevent & rachork & cubble \\
glass & save & shoket & akment \\
hill & sing & banten & keavose \\
saint & announce & gistock & lorchal \\
chapter & avoid & sarpel & hettel \\
chair & perform & soudelt & kosheam \\
task & divide & donter & vartglis \\
forest & define & credlo & tramunt \\
\hline & & &
\end{tabular}

\section{APPENDIX B}

\begin{tabular}{llll}
\hline $\begin{array}{l}\text { High-Base/ } \\
\text { Low-Plural } \\
\text { Nouns }\end{array}$ & $\begin{array}{c}\text { Low-Base/ } \\
\text { High-Plural } \\
\text { Nouns }\end{array}$ & \multicolumn{2}{c}{ Nonwords } \\
\hline island & statement & opet & ikol \\
county & product & atron & koner \\
river & window & clatig & palton \\
hotel & machine & vobget & spigol \\
treatment & artist & soabit & riscat \\
freedom & lady & roaken & pulase \\
dinner & region & mepshig & lassink \\
captain & payment & arftelt & niethob \\
kitchen & expense & bafteal & sardelt \\
failure & symbol & spolfez & kerfilt \\
danger & agent & flomert & woastilk \\
village & error & vartgliss & gloinvose \\
\hline
\end{tabular}




\section{APPENDIX C}

\begin{tabular}{llll}
\hline $\begin{array}{l}\text { Equal-Base/ } \\
\text { Low-Plural } \\
\text { Nouns }\end{array}$ & $\begin{array}{l}\text { Equal-Base/ } \\
\text { High-Plural } \\
\text { Nouns }\end{array}$ & \multicolumn{2}{c}{ Nonwords } \\
\hline death & problem & blent & arftelt \\
river & method & canim & blukin \\
floor & member & dreat & curfin \\
hall & nation & fint & dister \\
manner & month & gultan & flink \\
income & student & hestim & gistock \\
council & unit & keavole & ikol \\
dinner & product & loster & kosheam \\
kitchen & event & murstip & miver \\
failure & brother & niethob & norbrok \\
lord & song & ort & plef \\
valley & tree & plaret & spet \\
desk & leg & smed & tep \\
career & artist & treper & vobget \\
text & item & vorg & voke \\
vision & mile & wootik & trin \\
theme & aspect & vourg & soabit \\
lake & dollar & trop & reable \\
chest & weapon & strig & parbin \\
uncle & seed & retip & nart \\
\hline
\end{tabular}

(Manuscript received March 22, 1995;

revision accepted for publication July 10,1996.) 